\title{
Desk of the Editor
}

\section{K. S. Gopinath ${ }^{1}$}

Published online: 24 February 2016

(C) Indian Association of Surgical Oncology 2016

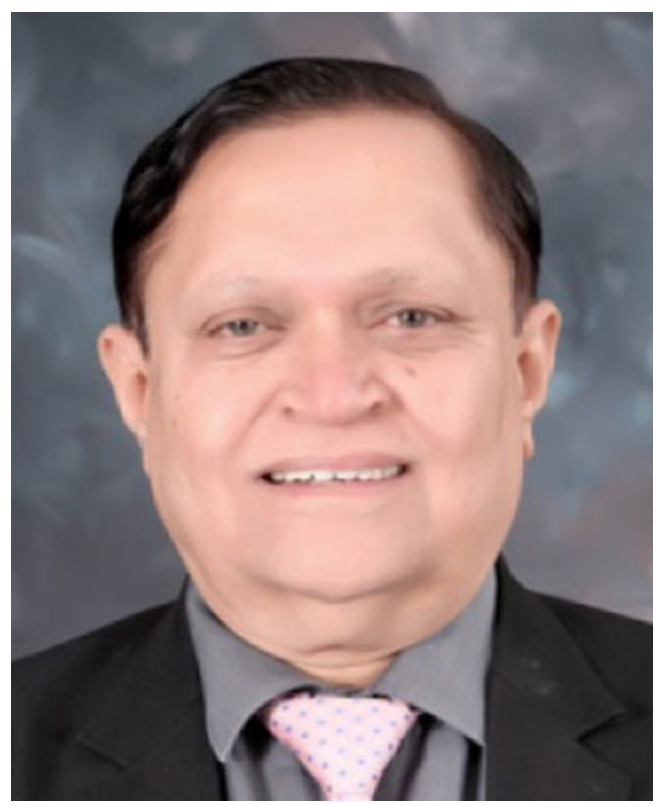

I am pleased to present you in this a challenging trend in management of Peritoneal Surface Malignancies. A few years ago, when I saw the debate on "HIPE" at ACSP by Prof. Sugar Baker VS Medical oncologist, the conclusion were the result of Prof. Sugar Baker was difficult to response.

K. S. Gopinath gopiijso@gmail.com

1 Ambuja Health Care, Patalamma Temple Street, Armugam Circle, Basavanagudi, Bangalore 560004, India
A few years later things changed, understanding of Biology of the Peritoneal surface metastasis changed, development of technology and aggressiveness of surgical procedures taken place. The concept of Primary and Secondary Cytoreductive surgery in adjuvant and Neo adjuvant setting changed, and started looking "Beyond".

Prof.Sugarbaker visited NATCON 2014 at Chennai and has the concept that the management of PSOGI should reach patient and professionals. The workshop was organized by my panel association IASO.

I really thank Dr. Aditi Bhat and Dr. Shabber Javeri who organized workshop and have development of surgical procedures, debates case discussion happened instantly. It benefitted may oncology professionals.

At the end while discussing Prof. Sugar Baker offered to be the guest editor, meticulously served all articles and submitted in time.

On behalf of the editorial board my special thanks to Prof. Sugar Bakers, all contributing authors, reviewer's, special thanks to Dr. Aditi Bhatt \& Dr. Shabber Zaveri for their help in bring out this issue.

Thanking you,

Regards,

Dr. K. S. Gopinath 